\title{
The outcomes of isolated ureteral resection and reconstruction in non-urologic cancer patients who underwent cytoreductive surgery (CRC) and hyperthermic intraperitoneal chemotherapy (HIPEC)
}

Şevket Barış Morkavuk ${ }^{* *}$ (i), Murat Güner ${ }^{2}$, Mesut Tez ${ }^{1}$ and Ali Ekrem Ünal ${ }^{3}$

\begin{abstract}
Background: Urinary system resections are performed during the cytoreductive surgery with hypertermic intraperitoneal chemotherapy (CRS-HIPEC). However, isolated ureter resection and reconstruction results are uncertain. The aim of this study was to evaluate the postoperative outcomes of isolated ureteral resection and reconstructions in patients who underwent CRC and HIPEC procedure.
\end{abstract}

Methods: A total of 257 patients that underwent CRC and HIPEC between 2015 and 2017 in the Department of Surgical Oncology, Faculty of Medicine, Ankara University, were retrospectively analyzed. Twenty patients that had undergone isolated ureteral resection and reconstruction were included in the study. Predisposing factors were investigated in patients who developed postoperative complications.

Results: The mean age of the patients was 55.1 years. The mean follow-up time of all the patients was 11.6 months. Postoperative mortality occurred in two patients. The mean PCI score was 13.9. Postoperative urologic complications were observed in eight patients after ureter reconstruction. There was no statistically significant difference between the groups in terms of reconstruction techniques and postoperative complications $(P=302)$. There was no correlation between age $(P=0.571)$ and gender $(P=0.161)$ with complications. CRS-HIPEC was performed mostly due to gynecologic malignancy. However, there was no correlation between the primary cancer diagnosis and the development of complications $(P=0.514)$. The hospital stay duration was higher in the group with complications (16.3 vs 8.8 days, $P=0.208$ ).

Conclusions: Ureteral resections and reconstructions can be performed for R0/1 resections in CRS-HIPEC operations. It leads to an increase in hospital stay. But there is no significant difference in the development of complications. In the management of complications, conservative approach was sufficient.

Keywords: Ureteral resection, Cytoreductive surgery, HIPEC

\footnotetext{
*Correspondence: drsbmor@yahoo.com

'Department of Surgical Oncology, Ankara City Hospital, Üniversiteler

Mahallesi, Bilkent Caddesi NO = 1, Onkoloji Binası, 6.Kat, Ankara, Turkey

Full list of author information is available at the end of the article
}

C The Author(s). 2019 Open Access This article is distributed under the terms of the Creative Commons Attribution 4.0 International License (http://creativecommons.org/licenses/by/4.0/), which permits unrestricted use, distribution, and reproduction in any medium, provided you give appropriate credit to the original author(s) and the source, provide a link to the Creative Commons license, and indicate if changes were made. The Creative Commons Public Domain Dedication waiver (http://creativecommons.org/publicdomain/zero/1.0/) applies to the data made available in this article, unless otherwise stated. 


\section{Background}

Peritoneal carcinomatosis is a disease characterized by peritoneal surface involvement of cancer cells. It is particularly seen in the late stages of gastrointestinal, gynecological cancers, and primary peritoneal malignancies. In selected patients, cytoreductive surgery (CRC) and hyperthermic intraperitoneal chemotherapy (HIPEC) are used for definitive treatment [1]. Respectively, due to the long operating time, multiple organ resections and chemotherapeutic agents, the CRC-HIPEC treatment has high morbidity $(14-56 \%)$ and mortality $(0.8-5 \%)$ rates [2]. Urinary system resections (bladder resection, nephrectomy, prostatectomy, and ureteral resection) are necessary at a rate of 7-20\% during the CRC-HIPEC procedure [3]. However, in the literature, there is no sufficient data about long-term outcomes of these urological interventions. A few studies reported that these interventions have increased postoperative morbidity, mortality, and hospital stay rates, but did not change overall survival rates [4]. On the other hand, there is no data in the literature about postoperative course of isolated ureter resection and reconstruction.

The aim of this study was to evaluate the postoperative outcomes of isolated ureteral resection and reconstructions in patients with non-urologic peritoneal cancer who underwent CRC and HIPEC procedure.

\section{Material and method \\ Patients}

A total of 257 patients that underwent CRC and HIPEC between 2015 and 2017 in the Department of Surgical Oncology, Faculty of Medicine, Ankara University, were retrospectively analyzed. Twenty-six patients were found who had undergone diversion or reconstruction procedures due to urinary system involvement. Two patients with peritoneal cancer index (PCI) above 20 and four patients that had undergone nephrectomy were excluded from the study. Twenty patients that had undergone isolated ureteral resection and reconstruction were included in the study.

\section{CRC and HIPEC procedure}

CRC procedure were performed as described by Sugarbaker [5]. Anastomoses were performed subsequent to HIPEC procedure. After placing an abdominal catheter, abdomen was closed and HIPEC was applied. Cisplatin $\left(90 \mathrm{mg} / \mathrm{m}^{2}\right)$ and mitomycin-C $\left(15 \mathrm{mg} / \mathrm{m}^{2}\right)$ were administered to the patients with ovarian cancer using closed abdomen technique at $42^{\circ}$ for $60 \mathrm{~min}$. For the patients with other cancer types, a combination of mitomycin-C $\left(15 \mathrm{mg} / \mathrm{m}^{2}\right)$ and carboplatin $\left(300 \mathrm{mg} / \mathrm{m}^{2}\right)$ was applied at $42^{\circ}$ for approximately $60 \mathrm{~min}$.

\section{Ureteral reconstruction}

Ureteral reconstruction was performed with ureteroureterostomy, transureteroureterostomy, ureteroneocystostomy, and Boari flap methods. Ureterosigmoid anastomosis was performed in patients that underwent pelvic exenteration. In this method, loop colostomy had been created in the first step; then, distal $5 \mathrm{~cm}$ of sigmoid loop colostomy was used as a conduit. Both ureters were anastomosed to the loop colostomy with a double-j catheter by using the Bricker technique. In this way, a second ostomy was not required, and a second intestinal loop was not used as a conduit. In addition, fecal contamination was prevented because the ureteric anastomosis was performed distally to the ostomy.

\section{Data analysis}

All statistical analyses were performed with SPSS v22.0. Mann-Whitney $U$ test was used for comparing continuous data. Fisher's exact test was used to compare categorical variables. Statistical significance was defined as $P<0.05$.

\section{Results \\ Patient profile}

In this study, 20 patients that underwent isolated ureter resection and reconstruction in CRC and HIPEC procedures were evaluated. When the demographic data were examined, the mean age of the patients was 55.1 years (range 32-87). Fourteen patients (70\%) were females, and six were males (30\%). The mean age was 54.2 years (range 37-78) for women and 57.3 years for men (range 32-87). Concerning the primary cancer diagnoses, 10 patients had gynecologic malignancies, seven had colorectal cancer, and three had retroperitoneal sarcomas. Fourteen patients (70\%) had undergone laparotomy in a different center and were referred to our clinic for CRC and HIPEC. Using preoperative imaging methods, hydronephrosis was detected in 12 patients. Hydronephrosis was on the left for five patients, right for four patients, and bilateral in seven patients (Table 1).

The mean follow-up time of all patients was 11.6 months ( 2 weeks-24 months) (Table 2). In hospital mortality occurred in two patients (2 of 20 patients). Eighteen patients were discharged and 5 of 18 patients died during follow-up period (mean survival time 11.6 months). Thirteen patients are still alive. Mean followup period for these 13 patients is 13.3 months.

\section{Surgical and postoperative outcomes}

Multiple organ resection was performed in 20 patients. The mean PCI score was 15.2 (range 12-20) for the patients with ovarian cancer and 12.6 (range 10-15) for those with colorectal cancer and retroperitoneal sarcoma. The median completeness of cytoreduction (CCR) index was 0 . 
Table 1 Demographic distrubition of the patients

\begin{tabular}{|c|c|}
\hline Sex & $n(\%)$ \\
\hline Male & $6(\% 30)$ \\
\hline Female & $14(\% 70)$ \\
\hline Age, year, mean $\pm S D$ & $55.15 \pm 14(32-87)$ \\
\hline \multicolumn{2}{|l|}{ Primary cancer diagnosis } \\
\hline Colorectal cancer & $7(\% 35)$ \\
\hline Gynecologic cancer & $10(\% 50)$ \\
\hline Retroperitoneal sarcoma & $3(\% 15)$ \\
\hline \multicolumn{2}{|l|}{ Preoperative hydronephrosis } \\
\hline No & $8(\% 40)$ \\
\hline Right & $4(\% 20)$ \\
\hline Left & $5(\% 25)$ \\
\hline Bilateral & $3(\% 15)$ \\
\hline \multicolumn{2}{|l|}{ Visceral organ resection } \\
\hline Low anterior resection & $7(\% 35)$ \\
\hline Total proctocolectomy & $2(\% 10)$ \\
\hline Total colectomy & $1(\% 5)$ \\
\hline Hemicolectomy & $2(\% 10)$ \\
\hline A.P.R & $2(\% 10)$ \\
\hline Pelvic exenteration & $3(\% 15)$ \\
\hline $\mathrm{TAH}+\mathrm{BSO}$ & $3(\% 15)$ \\
\hline \multicolumn{2}{|c|}{ Types of ureteral reconstructions } \\
\hline Ureteroureterostomy & $2(\% 10)$ \\
\hline Trans ureteroureterostomy & $6(\% 30)$ \\
\hline Ureteroneocystostomy & $5(\% 25)$ \\
\hline Boari flap & $4(\% 20)$ \\
\hline Ureterosigmoidostomy & $3(\% 15)$ \\
\hline $\mathrm{PCl}$, mean $\pm \mathrm{SD}$ (range) & $13.9 \pm 3(10-20)$ \\
\hline
\end{tabular}

$S D$ standard deviation, $P C l$ peritoneal carcinomatozis index, Min minimum, Max maximum, A.P.R abdomino perineal resection, $T A H+B S O$ total abdominal hysterectomy + bilateral salpingo-oophorectomy

When the urological surgical procedures were examined, it was determined that left ureteral resection had been performed in seven patients (35\%), right ureteral resection in eight patients (40\%), and bilateral partial ureteral resection in five patients (25\%). The reconstruction methods applied were ureteroureterostomy, transureteroureterostomy, ureteroneocystostomy, Boari flap procedure, and ureterosigmoidostomy.

The mean length of hospitalization was 11.9 days (range $6-32)$. Early mortality was seen in two patients (10\%), of whom one died due to pulmonary thromboembolism on the 15th postoperative day and the other on the 25th

Table 2 Follow-up time and length of hospital stay of all patients Follow-up time, month, mean \pm SD (range) $11.65 \pm 8(1-24)$ Lenght of hospital stay, day, mean \pm SD (range) $11.9 \pm 8(6-32)$ postoperative day due to disseminated intravascular coagulation.

According to Clavien-Dindo classification, major complication was seen in seven patients. Early mortality was seen in two patients (grade 5), and anastomosis leakage was detected in five patients (grade 3a). There were no complications seen due to intestinal anastomosis.

Postoperative urologic complications were observed in eight patients after ureter reconstruction. Early anastomosis leakage was detected in five patients $(10 \%)$ and late anastomosis stricture in three patients (15\%).

There was no statistically significant difference between the groups in terms of reconstruction techniques and postoperative complications $(P=0.302)$. In the anastomotic leakage group, there were two patients with Boari flap (40\%), one patient with ureteroureterostomy (20\%), one patient with transureteroureterostomy (20\%), and one patient with ureteroneocystostomy $(20 \%)$. Three patients that developed late stricture had undergone transureteroureterostomy (Table 3).

Of the eight patients with postoperative complications, four had transureteroureterostomy (50\%), two Boari flaps $(25 \%)$, one ureteroureterostomy $(12.5 \%)$, and one ureteroneocystostomy (12.5\%).

Concerning hospital stay duration, there was no statistically significant difference between patients who developed complication and who did not $(P=0.208)$. The mean hospital stay was $16.37 \pm 10$ days (range $7-32$ ) in the group with complications and $8.83 \pm 2$ days (range 6-13) in the group without complications.

The mean PCI was 13.5 in the complication group and 14.16 in the non-complication group, and there was no statistically significant difference between the two groups $(P=0.571)$.

For the management of complications, a unilateral percutaneous nephrostomy catheter was placed in patients who had anastomotic leakage. Bilateral percutaneous nephrostomy catheters were applied to patients that had undergone transureteroureterostomy. On a daily basis, urea creatinine was analyzed and compared both from abdominal drainage and the nephrostomy catheter. The anastomotic leakage was controlled by percutaneous nephrostomy in all patients. One month later, the nephrostomy catheters were withdrawn from the patients after confirming anastomosis integrity by opaque imaging methods.

In the evaluation of patients with late complications, hydronephrosis was observed in one patient at the fourth month, one patient at the fifth month, and one patient at the sixth month. These patients were first inspected using aureteroscope with a small diameter $(<8 \mathrm{~F})$. Balloon dilatation and double- $j$ recatheterization were performed due to the stricture in the anastomosis line. 
Table 3 Factor affecting urological complications

\begin{tabular}{|c|c|c|c|c|}
\hline & Urological complications (+) & Urological complications (-) & Total & $P$ value \\
\hline Age (years) & 52.6 & 56.8 & 55.1 & 0.571 \\
\hline Sex & 8 & 12 & 20 & 0.161 \\
\hline Male & 4 & 2 & 6 & \\
\hline Female & 4 & 10 & 14 & \\
\hline Primary cancer diagnosis & 8 & 12 & 20 & 0.514 \\
\hline Colorectal c. & 3 & 4 & 7 & \\
\hline Gynecologic c. & 3 & 7 & 10 & \\
\hline Retroperitoneal & 2 & 1 & 3 & \\
\hline Primary/recurrence & 8 & 12 & 20 & 0.642 \\
\hline Primary & 3 & 3 & 6 & \\
\hline Recurrence & 5 & 9 & 14 & \\
\hline Hydronephrosis & 8 & 12 & 20 & 0.126 \\
\hline No & 3 & 5 & 8 & \\
\hline Yes & 5 & 7 & 12 & \\
\hline Ureteral reconstructions & 8 & 12 & 20 & 0.302 \\
\hline Ureteroureterostomy & 1 & 1 & 2 & \\
\hline TransUreteroureterostomy & 4 & 2 & 6 & \\
\hline Ureteroneocystostomy & 1 & 4 & 5 & \\
\hline Boari flap & 2 & 2 & 4 & \\
\hline Ureterosigmoidostomy & 0 & 3 & 3 & \\
\hline $\mathrm{PCl}$ & 13.5 & 14.1 & 13.9 & 0.521 \\
\hline Colorectal c. & 13.3 & 13.2 & & \\
\hline Gynecologic c. & 15.3 & 15.1 & & \\
\hline Retroperitoneal s & 11 & 11 & & \\
\hline Length of hospital stay (day) & 16.3 & 8.8 & 11.9 & 0.208 \\
\hline
\end{tabular}

Mean survival was shown by Kaplan-Meier curve. There was no statistically significant difference between the groups about mean survival (log rank $P=0.710$ ). Two-year survival ratio through a month is shown in (Table 4).

\section{Discussion}

CRC combined with HIPEC is an increasingly accepted curative-intent option for selected patients with peritoneal carcinomatosis. This combined procedure is associated with high rates of potentially life-threatening complications. It has a complication rate of $50-70 \%$. Due to these high mortality and morbidity rates, the identification of patients who are more likely to benefit from CRS/HIPEC is of great clinical relevance. PCI and CCR are widely used in patient selection process, but these scores do not provide any information of the potential impact of an associated urologic procedure on both operative and long-term outcomes.

In our study, patients with a PCI value of 20 or below were included in the study group while those with a PCI greater than 20 underwent a debulking surgery to reduce tumor burden. Patients with a PCI value of 20 or higher are considered to have a poor prognosis. The common opinion is that this group of patients will not benefit from the CRC-HIPEC treatment [6]. There are studies on PCI and CCR in cases with various cancer diagnoses. Goere et al. reported the PCI cut-off value for survival as 17. In that study, patients that underwent palliative surgery using CRC-HIPEC were compared and it was found that this combined technique did not have any significant effect on the mean survival rate of patients with a PCI greater than 17. At the same time, authors also determine that postoperative complications were significantly higher in the CRC-HIPEC group [7].

Aggressive surgery to achieve CCR 0/1 increases the risk of morbidity and mortality in patients with high $\mathrm{PCI}$ values. In a study by Honere et al. found that the incidence of urinary fistula after urinary tract resection was significantly higher in patients with a PCI value above 20 [3]. To the best of our knowledge, there is no study in the literature investigating the PCI values after isolated 
Table 4 Overall survival according urological complications and average survival rates by months

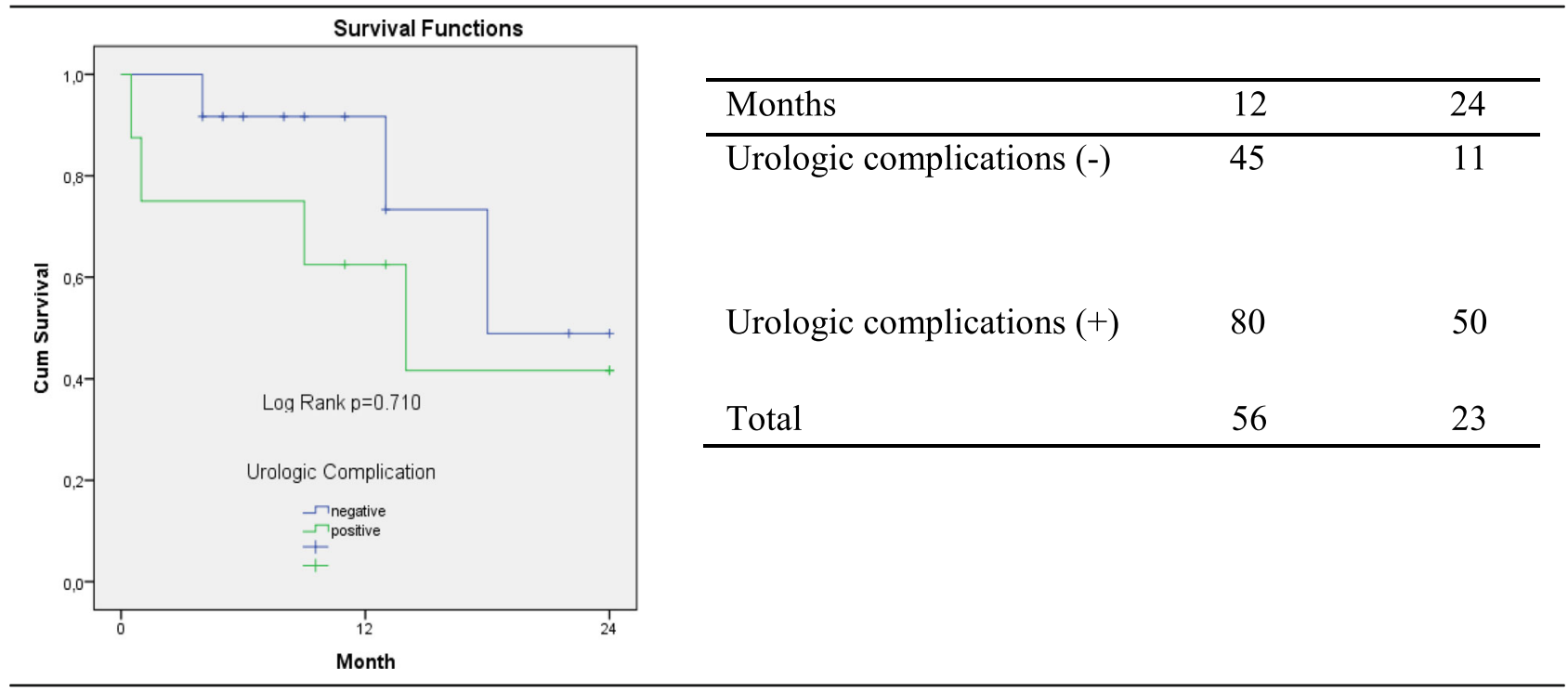

ureteral reconstruction. In the current study, we did not find any relationship between PCI height and complication after ureteral reconstruction. Contrary to expectation, the mean PCI was higher in without complications group.

During the CRC procedure, urinary system resections are performed at a rate of $7-20 \%$ to achieve clean surgical margins or due to iatrogenic injury [3]. Similar to the literature, in our study, urinary system resection was performed in 10.1\% (26 patients) of 257 patients who underwent CRC-HIPEC for the purpose of obtaining clean surgical margins. In addition, 7.7\% of the patients $(n=20)$ underwent isolated ureter resection.

There are publications in the literature evaluating the length of hospital stay after urinary system interventions with CRC-HIPEC. However, we did not find any studies on the effect of isolated ureteral reconstruction on hospital stay. In a study by Lyon et al., the duration of hospitalization was significantly longer in patients that underwent a urological procedure (cystectomy, nephrectomy, ureteral repair, ureteral reconstruction, seminal gland resection) [8]. In another study conducted by Tan et al., hospital stay was found to be longer in patients that underwent a urological intervention [9]. Nevertheless, in both studies, the patients were grouped according to urologic interventions, rather than complications. The complication development and length of hospital stay were not correlated. In contrast, we grouped the patients according to the presence of complications after isolated ureter reconstruction. We found a longer hospital stay in the group with complications, albeit with no statistical significance.
In the evaluation of complications after ureteral reconstruction, early period anastomotic leakage was seen at a higher rate in patients that had received a Boari flap, and late period stricture in those that had undergone transureteroureterostomy. In transureteroureterostomy, the iatrogenic incision made in the ureter tissue means an additional anastomosis, which, we think, increases the development of strictures in the following period. Wenske et al., who compared the ureteroneocystostomy, Boari flap and psoas hitch flap methods, reported that minor and major complications were rare and there was no significant difference between these techniques in terms of the incidence of complications [10]. In another study, Iwaszko et al. observed that the most common complication after transureteroureterostomy was anastomotic leakage. A delayed anastomotic stricture developed in $4 \%$ of the cases, of whom $10 \%$ required relaparotomy during the 6-year follow-up [11].

Studies have shown that the possibility of postoperative complications is increased in CRC-HIPEC cases undergoing a urinary system intervention. Lyon et al. reported that the rate of complications was significantly higher following urinary system interventions compared to cases that did not undergo such an intervention [8]. Early complications include anastomotic leakage, obstruction, fistula, and pyelonephritis while obstruction and urinary tract stones are usually seen as late complications. In our study, only complications related to ureteral reconstruction were examined. In our patients, anastomotic leakage was observed as an early complication and stricture as a late complication. In the management of complications, the conservative approach was sufficient, and relaparotomy was not required. Anastomotic leakage was controlled by percutaneous 
nephrostomy. For the management of strictures, after ureteroscopy, ureteral continuity was maintained through balloon dilatation. In the literature, Leapman et al. treated ureteral obstruction and stricture using double-j catheterization, and Honore et al. used percutaneous nephrostomy for the treatment of ureteral fistulas $[3,4]$.

We did not find any relationship between hydronephrosis and complications after ureteral reconstruction. Guang et al. showed that the presence of preoperative hydronephrosis was not a factor in the development of urologic complications [12]. Similarly, in a study by Leapmanet al., three of 30 patients with postoperative urologic complications had preoperative hydronephrosis [4]. In our study, we observed that the presence of hydronephrosis or lateralization did not increase the development of complications after ureteral reconstruction.

In our cases of ureterosigmoidostomy anastomoses, we preferred to use the Bricker technique. The Bricker and Wallace methods are frequently used for ureterointestinal anastomoses. In a large-scale meta-analysis of 658 patients with a total of 1217 anastomoses, the Bricker and Wallace techniques were compared and did not significantly differ in terms of the development of complications [13]. In the current study, early and late complications were not observed in any of the patients that had undergone ureterosigmoidostomy.

Our study has certain deficiencies and lack of data. Due to its retrospective nature, some patients could not be included in the study. Therefore, a relatively small number of patients were examined. Furthermore, our 5 years survival rates have not yet been clarified since the patient follow-up continues.

\section{Conclusion}

In cases with appropriate PCI and CCS values, ureteral resection and reconstruction can be safely performed during CRC-HIPEC. Despite the increase in hospitalization duration, there is no significant increase in complication development. Various parameters have been studied regarding postoperative complications but we did not identify any predisposing factor. There is also no difference between reconstruction methods in terms of complications. Possible complications can be controlled by the conservative approach or relaparotomy.

\section{Acknowledgements}

Not applicable

\section{Authors' contributions}

SBM contributed to the manuscript editing and preparation of the manuscript. MG contributed to the quality control of data and algorithms of the manuscript. MT contributed to the statistical analysis of the manuscript. AEÜ contributed to the study concepts and design of the manuscript. All authors read and approved the final manuscript.

\section{Funding}

Not applicable
Availability of data and materials

The datasets used and/or analyzed during the current study are available from the corresponding author on reasonable request.

\section{Ethics approval and consent to participate}

Approval was received from ethics committee of Ankara University for the study named "The outcomes of isolated ureteral resection and reconstruction in non-urologic cancer patients who underwent cytoreductive surgery (CRC) and hyperthermic intraperitoneal chemotherapy (HIPEC)". Confirmation number is 18-1197-18.

\section{Consent for publication}

Not applicable

\section{Competing interests}

The authors declare that they have no competing interests.

\section{Author details}

${ }^{1}$ Department of Surgical Oncology, Ankara City Hospital, Üniversiteler Mahallesi, Bilkent Caddesi N0 = 1, Onkoloji Binası, 6.Kat, Ankara, Turkey. ${ }^{2}$ Department of General Surgery, Usak Research and Training Hospital, Usak, Turkey. ${ }^{3}$ Department of Surgical Oncology, Ankara University Faculty of Medicine, Ankara, Turkey.

Received: 10 October 2019 Accepted: 16 December 2019

Published online: 26 December 2019

\section{References}

1. Sugarbaker PH, Jablonski KA. Prognostic features of 51 colorectal and 130 appendiceal cancer patients with peritoneal carcinomatosis treated by cytoreductive surgery and intraperitoneal chemotherapy. Ann Surg. 1995; 221(2):124.

2. Stewart JH, Shen P, Levine EA. Intraperitoneal hyperthermic chemotherapy for peritoneal surface malignancy: current status and future directions. Ann Surg Oncol. 2005;12(10):765-77.

3. Honoré C, Souadka A, Goéré D, Dumont F, Deschamps F, Elias D. HIPEC for peritoneal carcinomatosis: does an associated urologic procedure increase morbidity? Ann Surg Oncol. 2012;19(1):104-9.

4. Leapman MS, Jibara G, Tabrizian P, Franssen B, Yang M-J, Romanoff A, et al. Genitourinary resection at the time of cytoreductive surgery and heated intraperitoneal chemotherapy for peritoneal carcinomatosis is not associated with increased morbidity or worsened oncologic outcomes: a case-matched study. Ann Surg Oncol. 2014;21(4):1153-8.

5. Sugarbaker $\mathrm{PH}$. Cytoreductive surgery using peritonectomy and visceral resections for peritoneal surface malignancy. Trans Gastrointest Cancer. 2013;2(2):54-74.

6. Glockzin G, Schlitt HJ, Piso P. Peritoneal carcinomatosis: patients selection, perioperative complications and quality of life related to cytoreductive surgery and hyperthermic intraperitoneal chemotherapy. World J Surg Oncol. 2009:7(1):5.

7. Goéré D, Souadka A, Faron M, Cloutier AS, Viana B, Honoré C, et al. Extent of colorectal peritoneal carcinomatosis: attempt to define a threshold above which HIPEC does not offer survival benefit: a comparative study. Ann Surg Oncol. 2015;22(9):2958-64.

8. Lyon TD, Turner RM II, Nikonow TN, Wang L, Uy J, Ramalingam L, et al. Effect of a concomitant urologic procedure on outcomes following cytoreductive surgery with hyperthermic intraperitoneal chemotherapy. J Surg Oncol. 2016;113(2):218-22.

9. Tan GHC, Shannon NB, Chia CS, Lee LS, Soo KC, Teo MCC. The impact of urological resection and reconstruction on patients undergoing cytoreductive surgery (CRS) and hyperthermic intraperitoneal chemotherapy (HIPEC). Asian J Urol. 2018:5(3):194-8

10. Wenske S, Olsson CA, Benson MC. Outcomes of distal ureteral reconstruction through reimplantation with psoas hitch, Boari flap, or ureteroneocystostomy for benign or malignant ureteral obstruction or injury. Urology. 2013;82(1):231-6.

11. Iwaszko MR, Krambeck AE, Chow GK, Gettman MT Transureteroureterostomy revisited: long-term surgical outcomes. J Urol. 2010;183(3):1055-9. 
12. Tan YG, Tan G, Tan D, Chia CS, Ang DY, Teo MC. Urological reconstruction after pelvic oncological surgery: a single institution experience. Asian J Surg. 2017:40(5):389-95.

13. Davis NF, Burke JP, McDermott T, Flynn R, Manecksha RP, Thornhill JA. Bricker versus Wallace anastomosis: a meta-analysis of ureteroenteric stricture rates after ileal conduit urinary diversion. Can Urol Assoc J. 2015; 9(5-6):E284.

\section{Publisher's Note}

Springer Nature remains neutral with regard to jurisdictional claims in published maps and institutional affiliations.

Ready to submit your research? Choose BMC and benefit from:

- fast, convenient online submission

- thorough peer review by experienced researchers in your field

- rapid publication on acceptance

- support for research data, including large and complex data types

- gold Open Access which fosters wider collaboration and increased citations

- maximum visibility for your research: over $100 \mathrm{M}$ website views per year

At BMC, research is always in progress.

Learn more biomedcentral.com/submissions 